\title{
Survival of patients with distal esophageal and gastric cardia tumors: A population-based analysis of gastroesophageal junction carcinomas
}

\author{
Bryan A. Whitson, MD, PhD, ${ }^{\text {a }}$ Shawn S. Groth, MD, ${ }^{\text {a }}$ Zhongze Li, MS, ${ }^{b}$ Robert A. Kratzke, MD, ${ }^{\text {a,c }}$ and \\ Michael A. Maddaus, MD
}

\begin{abstract}
Objective: Distal esophageal tumors and gastric cardia tumors, although only physically separated by centimeters, have different staging systems and are usually treated differently. We hypothesized that gastroesophageal junction adenocarcinomas (eg, gastric cardia and distal esophageal tumors) were not distinct entities and had similar survival.
\end{abstract}

\begin{abstract}
Methods: Using the Surveillance, Epidemiology, and End Results database (1988-2005), we identified patients with adenocarcinomas of the distal esophagus $(\mathrm{n}=1474)$ and gastric cardia $(\mathrm{n}=192)$. We performed an unadjusted survival analysis using the Kaplan-Meier method, and we used a Cox proportional hazards regression model to adjust for potential confounding covariates. A 2-sided significance level was used for all statistical testing.
\end{abstract}

Results: Even after adjusting for potential confounding covariates (location, stage, race, cancer-directed surgery, and radiation therapy), we found no significant difference between distal esophageal and gastric cardia tumors with regard to overall (hazard ratio, 1.18; 95\% confidence interval, 0.99-1.41) and cancer-specific (hazard ratio, $1.09 ; 95 \%$ confidence interval, $0.90-1.31$ ) survival. Both cancer-directed surgery (hazard ratio, $0.45 ; 95 \%$ confidence interval, $0.37-0.54$ ) and radiation therapy (hazard ratio, $0.63 ; 95 \%$ confidence interval, $0.55-0.71$ ) had a beneficial influence on survival.

Conclusion: Through a large, population-based analysis of gastric cardia and distal esophageal adenocarcinomas, we found that patients with gastroesophageal junction adenocarcinomas have similar survival rates. Cancer-directed surgery was beneficial. Adenocarcinomas of the gastroesophageal junction are not distinct entities delineated by anatomic boundaries and as such should be managed by one skilled in both esophageal and gastric resections. (J Thorac Cardiovasc Surg 2010;139:43-8)

Gastroesophageal junction (GEJ) tumors include both distal esophageal (DE; Siewert type I) and gastric cardia (GC; Siewert type II) carcinomas. ${ }^{1}$ Although they are physically separated by only a few centimeters, they have distinct American Joint Committee on Cancer (AJCC) staging systems and are often treated differently. ${ }^{2}$

The literature lacks large population-based comparisons of the survival time of patients with DE and GC tumors. We evaluated a large, US population-based cancer registry to understand better the implications of tumor location for patient survival.

\section{MATERIALS AND METHODS}

We conducted a retrospective cohort study using the Surveillance, Epidemiology, and End Results (SEER) database of patients 18 years and older

\footnotetext{
From the Department of Surgery, Division of Thoracic and Foregut Surgery, ${ }^{\text {a }}$ University of Minnesota; the Biostatistics Core, ${ }^{\mathrm{b}}$ University of Minnesota Cancer Center; and the Department of Medicine, Division of Hematology, Oncology, and Transplantation, ${ }^{\mathrm{c}}$ University of Minnesota, Minneapolis, Minn.

Presented at the American Society of Clinical Oncology 2008 Annual Meeting, Chicago, Ill, May 30-June 3, 2008.

Received for publication July 3, 2008; revisions received March 26, 2009; accepted for publication April 12, 2009; available ahead of print June 15, 2009.

Address for reprints: Michael A. Maddaus, MD, University of Minnesota Department of Surgery, MMC 207, 420 Delaware St SE, Minneapolis, MN 55455 (E-mail: madda001@umn.edu).

0022-5223/\$36.00

Copyright (C) 2010 by The American Association for Thoracic Surgery

doi:10.1016/j.jtcvs.2009.04.011
}

with adenocarcinomas of the distal esophagus or GC. ${ }^{3}$ Our goal was to evaluate the effect of tumor location on patients' overall and cancer-specific survival times. We collected information on patient characteristics (age, race, and sex), tumor characteristics (histologic type, grade, stage, and location), and treatment (whether they underwent cancer-directed surgery, radiation therapy, or both). For our analysis, we defined cancer-directed surgery as either esophagectomy or gastrectomy. Although SEER defines locally ablative or excisional procedures as cancer-directed therapy, we did not. Those patients who were coded as having undergoing "beam radiation" were classified as having received radiation. The Human Subjects Committee of the University of Minnesota determined that our study was exempt from formal review by the Institutional Review Board.

\section{Sample Selection}

For our analysis, we used the "digestive diseases other" subregistry of the SEER database (1973-2005). Patients were staged according to the AJCC Cancer Staging Manual, sixth edition. ${ }^{2}$ SEER registries began collecting data on lymph node metastasis in 1988, and therefore this study represents data collected by the SEER registries from 1988 through 2005. We excluded information obtained by the Louisiana SEER registry in 2005 because of the negative effect of Hurricane Katrina on data collection.

To select patients for inclusion in our study, we used the following topography codes (in parentheses) of the International Classification of Disease for Oncology, third edition, ${ }^{4}$ for each anatomic location in the esophagus: distal esophagus (C152 and C155) and GC (C160). Because few patients with GC tumors have squamous cell carcinomas $(3.8 \%$ incidence at the GC compared with $41 \%$ incidence at the distal esophagus), we limited our analysis to patients with adenocarcinomas (International Classification of Disease for Oncology, third edition, morphology codes 4: 8140-8145). We excluded patients with more than 1 primary tumor. Because they were unlikely to have received aggressive cancer treatment, we 


$$
\begin{aligned}
& \text { Abbreviations and Acronyms } \\
& \qquad \begin{aligned}
\text { AJCC } & =\text { American Joint Committee on Cancer } \\
\text { DE }= & \text { distal esophageal } \\
\text { GC } & =\text { gastric cardia } \\
\text { GEJ }= & \text { gastroesophageal junction } \\
\text { SEER }= & \text { Surveillance, Epidemiology, and End } \\
& \text { Results }
\end{aligned}
\end{aligned}
$$

excluded patients with metastatic disease and patients for whom their only reporting source was a hospice/nursing home, autopsy, or death certificate.

\section{Statistical Analysis}

For all analyses, we used SAS 9.1.3 software (SAS Institute, Inc, Cary, NC). Where appropriate, results are reported as means \pm standard deviations. Because of a lack of longer-term follow-up data, we censored our survival analysis at 5 years. To compare unadjusted overall and cancer-specific survival between histologic groups and between tumor locations, we used the Kaplan-Meier method. In the SEER databases the survival time coding is in monthly increments from the date of the diagnosis to either the date of death, the date last known to be alive, or the follow-up cutoff date of that particular database edition. To adjust our survival analysis for potential confounding variables, we used a Cox proportional hazard regression model. For all analyses, we used a 2-sided $\alpha$ value of .05.

\section{RESULTS}

\section{Sample Description}

Of the 237,674 patients in the SEER "digestive diseases other" subregistry, we identified 1666 patients who met our inclusion criteria. We initially evaluated the overall aggregate survival of midthoracic esophageal, DE, GC, and gastric body or fundus tumors (Figure 1, A) and found that the midthoracic esophageal tumors had the worst survival and gastric body or fundus tumors had the best survival ( $P$ $<$.0001). When we limited our analysis to those tumors of the distal esophagus and GC (ie, GEJ tumors), we found no difference $(P=.13)$ in survival rates (Figure $1, B)$.

Squamous cell carcinomas of the GC were reported in only $3.8 \%$ of the patients. Therefore we decided to limit our analysis to adenocarcinomas of the GEJ (Figure 2, $A$ ). For the DE and GC tumors, there was no significant difference in age, sex, or tumor grade (Table 1). Patients with DE tumors were more likely to be nonwhite. Patients with GC tumors were more likely to have stage I and IV disease. In addition, the patients with GC tumors underwent a significantly higher rate of cancer-directed surgery, whereas the patients with DE tumors had a significantly higher rate of radiation treatment. The mean tumor size in both groups was just over $5.5 \mathrm{~cm}$. The patients with GC tumors had a higher number of lymph nodes identified at resection.

\section{Survival}

We evaluated the effect of stage on unadjusted overall and cancer-specific survival rates. To be concise, only the cancer-specific survival evaluations are presented in this article

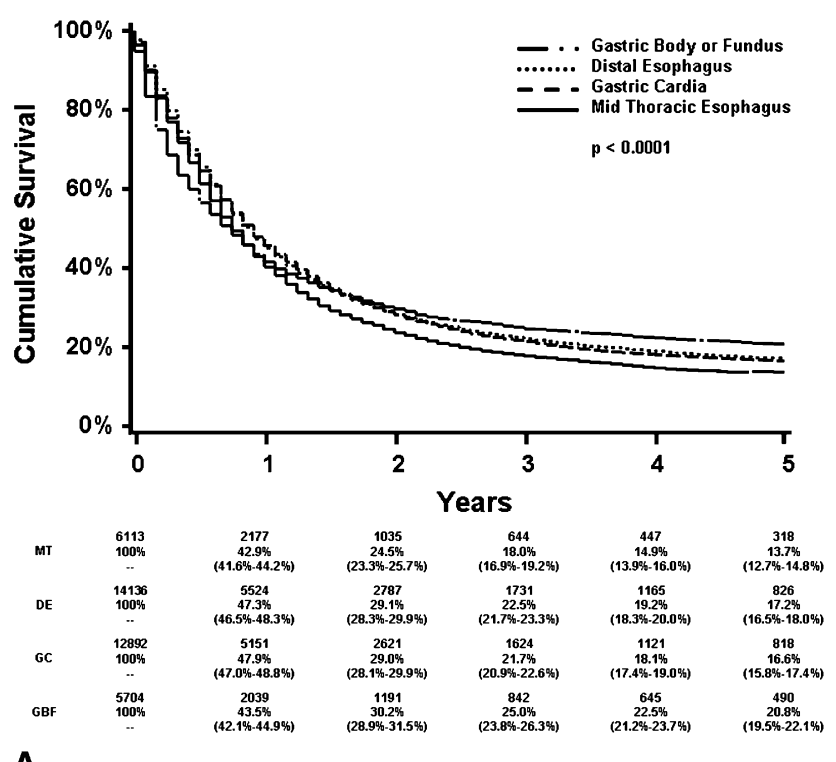

A

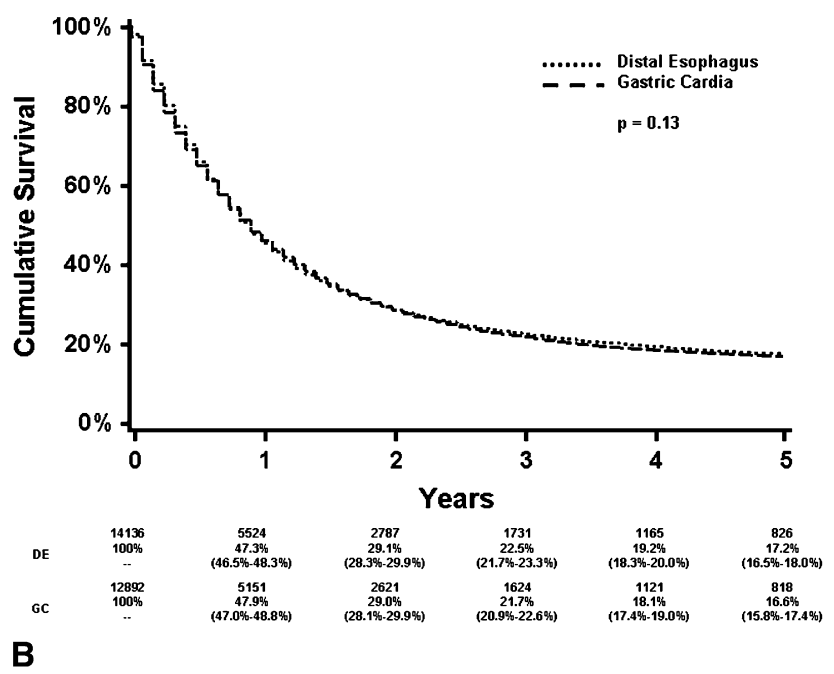

FIGURE 1. Cancer-specific survival of patients with midthoracic esophageal, distal esophageal, gastric cardia, and gastric body or fundus tumors ( $P$ $<.0001, \log$-rank test; A), as well as those of the gastroesophageal junction, distal esophageal, and gastric cardia $(P=.13, \log$-rank test; $\mathrm{B})$, for all stages by using the Kaplan-Meier method. In the table along the abscissa, for each location on the far left, the 3 rows correspond with the number at risk, the proportion surviving at that time point, and the corresponding $95 \%$ confidence interval at that time point. $M T$, Midthoracic esophagus; $D E$, distal esophagus; $G C$, gastric cardia; $G B F$, gastric body or fundus.

(Figure 2). Only those patients with stage III disease had significantly different survival times (Figure 2,D).

When we stratified our Kaplan-Meier analysis by T stage (instead of AJCC stage), we found no significant differences in cancer-specific survival rates for $\mathrm{DE}$ and $\mathrm{GC}$ adenocarcinomas: T1 $(P=.79)$, T2 $(P=.85)$, T3 $(P=.77)$, and T4 $(P=.33)$.

We used a Cox proportional hazard regression model to adjust for potential confounding variables on overall or 

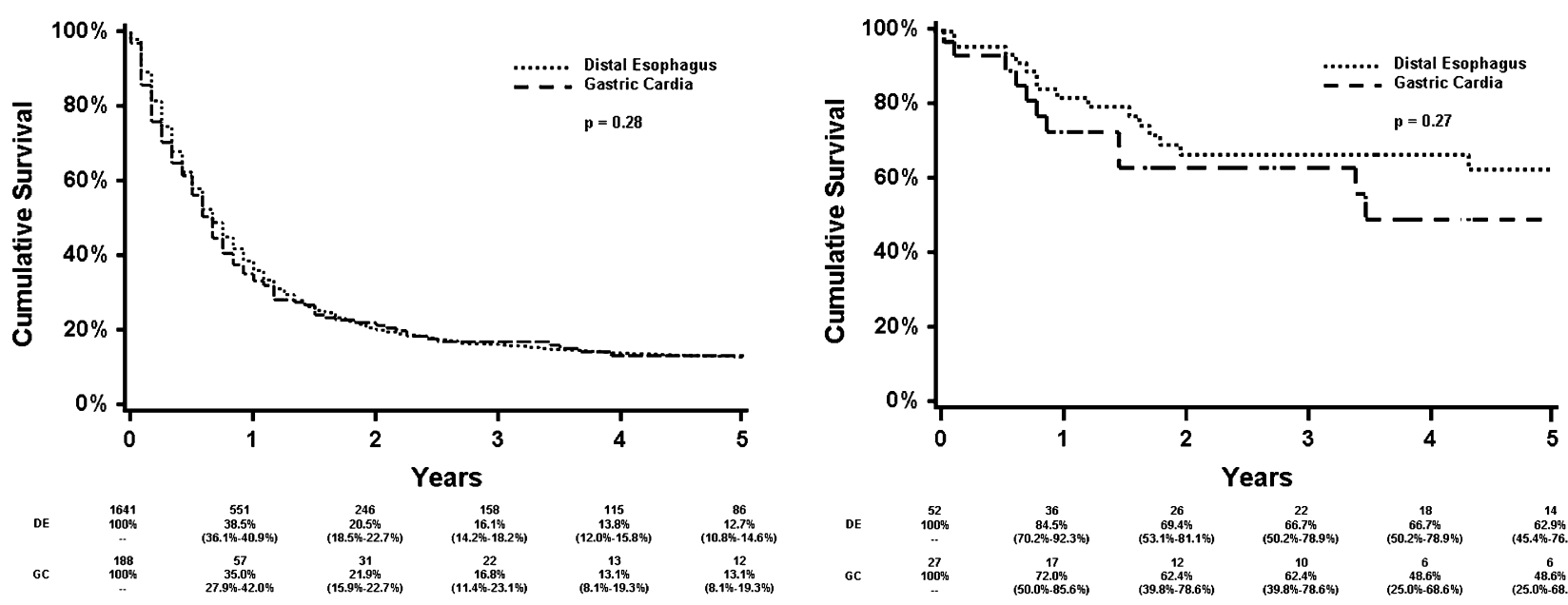

A
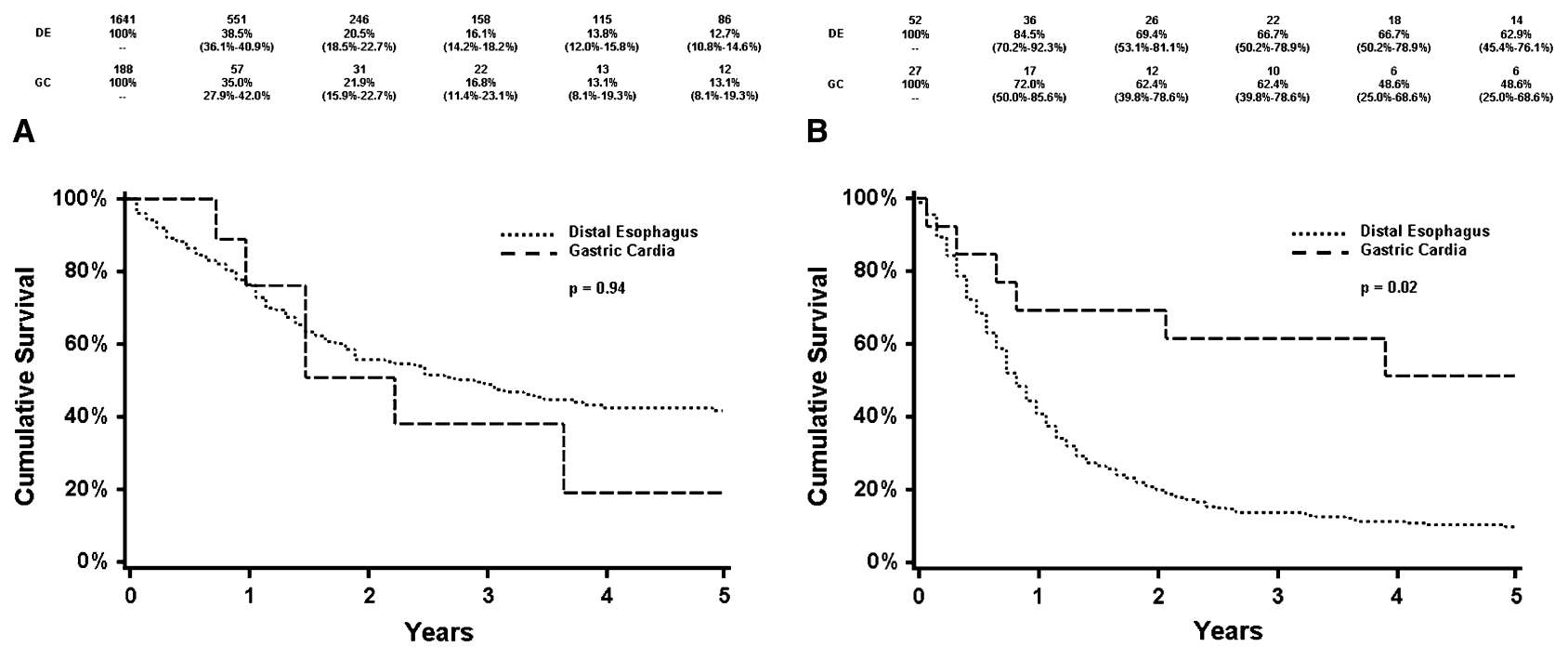

B
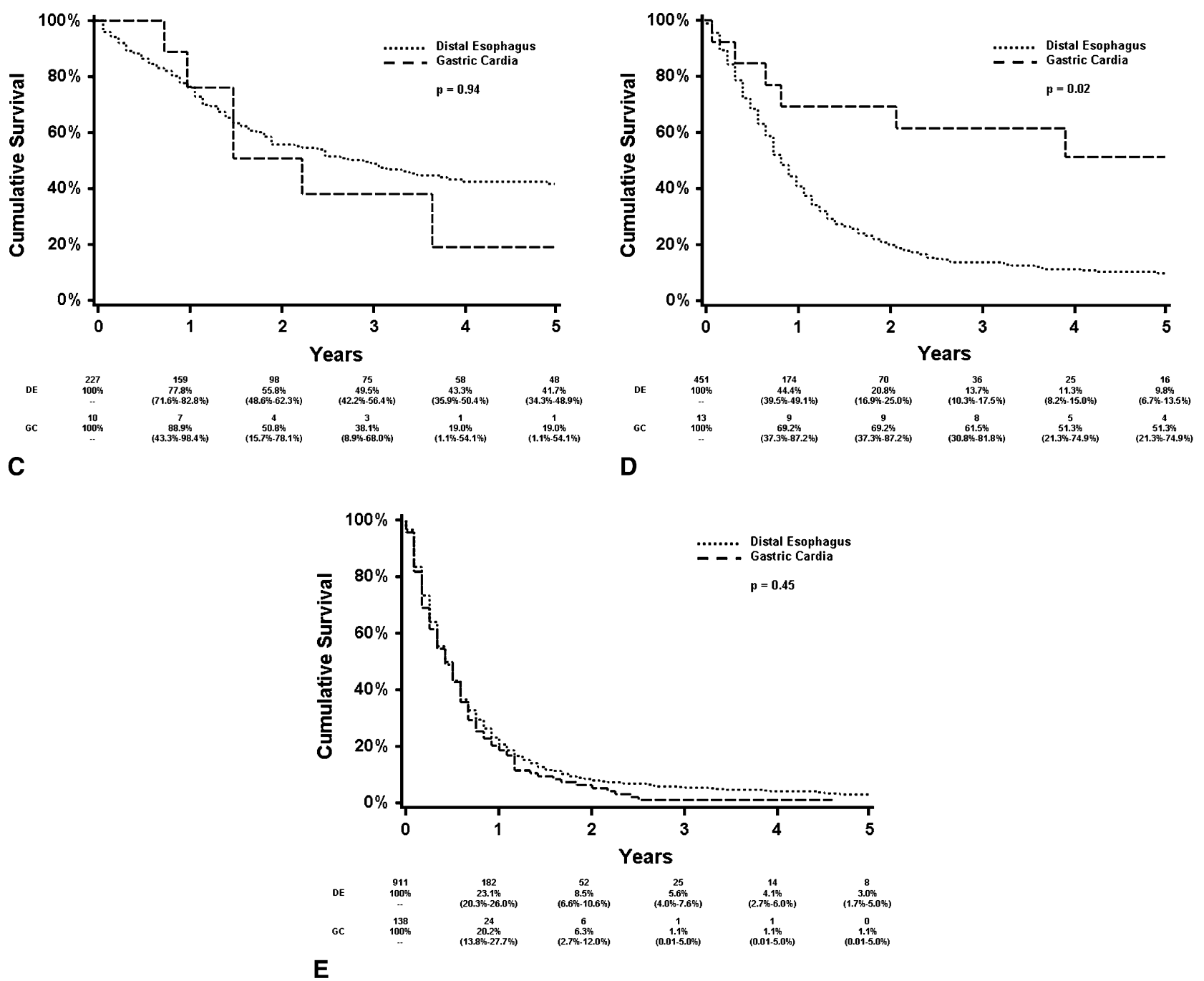

FIGURE 2. Cancer-specific survival, determined by using the Kaplan-Meier method, of patients with gastroesophageal adenocarcinomas for all stages in aggregate $(P=.28, \log$-rank test; A) and for stage I $(P=.27, \log$-rank test; B), stage II $(P=.94, \log$-rank test; C), stage III $(P=.02$, log-rank test; D), and stage IV $(P=.45$, log-rank test; E). In the table along the abscissa, for each location on the far left, the 3 rows correspond with the number at risk, the proportion surviving at that time point, and the corresponding $95 \%$ confidence interval at that time point. $D E$, Distal esophagus; $G C$, gastric cardia. 
TABLE 1. Study characteristics by tumor location

\begin{tabular}{|c|c|c|c|}
\hline & Distal esophagus & Gastric cardia & P value* \\
\hline No. & 1474 & 192 & \\
\hline Age at diagnosis (y) & $63.9 \pm 11.4$ & $65 \pm 12.2$ & .48 \\
\hline Female/male sex & $25 \% / 75 \%$ & $28.1 \% / 71.9 \%$ & .35 \\
\hline \multicolumn{4}{|l|}{ Race } \\
\hline White & $62.5 \%$ & $72.8 \%$ & .02 \\
\hline Black & $25.5 \%$ & $19.4 \%$ & \\
\hline Other & $12.0 \%$ & $7.9 \%$ & \\
\hline $\begin{array}{l}\text { Mean size } \\
\text { of tumor }(\mathrm{cm})\end{array}$ & $5.8 \pm 5.5$ & $5.6 \pm 2.6$ & .84 \\
\hline Mean no. of positive LNs & $0.9 \pm 2.1$ & $2.2 \pm 3.3$ & .004 \\
\hline $\begin{array}{l}\text { Mean total } \\
\text { no. of LNs }\end{array}$ & $2.4 \pm 6.1$ & $5.4 \pm 8.8$ & .06 \\
\hline $\begin{array}{l}\text { Cancer-directed surgery } \\
\text { (yes) }\end{array}$ & $26.3 \%$ & $44.3 \%$ & $<.0001$ \\
\hline Radiation therapy (yes) & $54.3 \%$ & $32.6 \%$ & $<.0001$ \\
\hline \multicolumn{4}{|l|}{ Grade } \\
\hline Well differentiated & $5.1 \%$ & $5.7 \%$ & .20 \\
\hline $\begin{array}{l}\text { Moderately } \\
\text { differentiated }\end{array}$ & $32.1 \%$ & $32.3 \%$ & \\
\hline Poorly differentiated & $46.3 \%$ & $52.1 \%$ & \\
\hline Undifferentiated & $2.0 \%$ & $1.6 \%$ & \\
\hline Unknown & $14.4 \%$ & $8.3 \%$ & \\
\hline \multicolumn{4}{|l|}{ AJCC stage } \\
\hline Stage I & $3.6 \%$ & $14.1 \%$ & $<.0001$ \\
\hline Stage II & $12.1 \%$ & $5.2 \%$ & \\
\hline Stage III & $21.3 \%$ & $7.3 \%$ & \\
\hline Stage IV & $63 \%$ & $73.4 \%$ & \\
\hline
\end{tabular}

Data are reported as percentages or means and standard deviations. Because of rounding, categories might not sum to $100 \%$. LNs, Lymph nodes; AJCC, American Joint Committee on Cancer. *All $P$ values are for between-group comparisons.

cancer-specific patient survival rates (Table 2). We found no significant difference in either overall or cancer-specific survival rates between patients with DE tumors and patients with GC tumors. Increasing stage was associated with a worse prognosis. Both cancer-directed surgery and radiation had a beneficial effect on survival.

\section{DISCUSSION}

DE and GC carcinomas have distinct AJCC staging systems, ${ }^{2}$ even though they are physically separated by only a few centimeters and are often classified as arising from the GEJ. In addition, because these 2 tumors arise near the confluence of the esophagus and stomach, their optimal treatment has been debated in part because tumors of the esophagus and stomach have classically been treated differently and confer different prognoses. Consequently, various operative approaches to esophagectomy (ie, transhiatal or transthoracic) ${ }^{5-7}$ and gastrectomy ( with $^{8}$ or without $^{9}$ thoracotomy), various margin lengths $(5-10 \mathrm{~cm}),{ }^{8,10-12}$ various extents of lymphadenectomy (1-field [D1 ${ }^{13,14}$ or D2 ${ }^{15,16}$ ], 2-field, ${ }^{9,17}$ or 3-field ${ }^{18,19}$ ), and various neoadjuvant and adjuvant treatment regimens ${ }^{20-22}$ have been advocated. There
TABLE 2. Cox proportional hazards regression models for overall and cancer-specific survival analysis of adenocarcinomas of the gastroesophageal junction*

\begin{tabular}{lcc}
\hline \multicolumn{1}{c}{ Variable } & $\begin{array}{c}\text { All-cause mortality, } \\
\text { HR }(\mathbf{9 5} \% \mathbf{C I})\end{array}$ & $\begin{array}{c}\text { Cancer-specific } \\
\text { mortality, HR } \mathbf{( 9 5} \% \mathbf{C I})\end{array}$ \\
\hline $\begin{array}{l}\text { Tumor location } \\
\text { Distal esophagus }\end{array}$ & 1.00 (reference) & 1.00 (reference) \\
Gastric cardia & $1.18(0.99-1.41)$ & $1.09(0.90-1.31)$ \\
AJCC stage & & \\
$\quad$ Stage I & 1.00 (reference) & 1.00 (reference) \\
Stage II & $1.4(0.95-2.07)$ & $1.5(0.95-2.37)$ \\
Stage III & $2.92(2.20-4.24)$ & $3.28(2.14-5.04)$ \\
Stage IV & $3.99(2.76-5.77)$ & $4.62(3.02-7.08)$ \\
Race & & \\
White & 1.00 (reference) & 1.00 (reference) \\
Black & $1.17(1.02-1.35)$ & $1.19(1.02-1.38)$ \\
Other & $0.82(0.67-1.01)$ & $0.92(0.74-1.15)$ \\
Cancer-directed surgery & & \\
No & 1.00 (reference) & 1.00 (reference) \\
Yes & $0.52(0.44-0.61)$ & $0.45(0.37-0.54)$ \\
Radiation & & \\
No & 1.00 (reference) & 1.00 (reference) \\
Yes & $0.59(0.24-1.43)$ & $0.63(0.55-0.71)$ \\
\hline$H R$, Hazard ratio; $C I$, confidence interval; $A J C C$, American Joint Committee on Can- \\
cer. *Hazard ratios adjusted for cancer registry (data not shown).
\end{tabular}

is no consensus regarding the optimal treatment of these tumors.

Given the heterogeneity of the epidemiologic characteristics and patterns of lymphatic spread of these tumors, Siewert and Stein devised the following classification scheme: type I (DE carcinomas), type II (true GC carcinomas), and type III (subcardial carcinomas). Their scheme facilitates the study of these tumors and allows for more accurate comparison of data between centers. ${ }^{1}$ Analyses of the effect of location of GEJ tumors on overall and cancerspecific survival in the literature have been limited to single-institution series. Therefore we used a large, population-based cancer registry to assess the influence of tumor location on survival rates for patients with adenocarcinomas of the GEJ.

\section{Sample Model}

After adjusting for potential confounding covariates (including histologic type and stage), we found that the survival rates for adenocarcinomas of the distal esophagus (type I) and GC (type II) were similar. For patients who are potential candidates for curative resection, treatment should be tailored to achieve an $\mathrm{R} 0$ resection (including appropriate margins) and an adequate lymphadenectomy.

Our results are in agreement with those of other studies in the literature that examined the association between GEJ tumor location and patient survival rates. Wijnhoven and colleagues ${ }^{23}$ performed a retrospective review of 252 patients with DE or GC adenocarcinomas who underwent 
a transhiatal esophagectomy from January 1987 through December 1996. In their multivariate analysis they found no significant difference in survival rates between patients with DE tumors and patients with GC tumors. In a series of more than 1000 consecutive patients, Siewert and associates ${ }^{9}$ noted no significant difference in survival rate between patients with DE tumors (Siewert type I) and patients with GC tumors (Siewert type II). Unlike our study, however, Siewert and associates noted that patients with gastric body or fundus tumors (Siewert type III) had a significantly worse prognosis than patients with DE tumors or patients with GC tumors.

Interestingly, in our study there were a greater number of lymph nodes identified in patients with GC tumors than in patients with esophageal tumors. This difference might be due to more completely defined practice guidelines for an adequate lymphadenectomy for gastric carcinomas; a D1 dissection should be performed in which at least $15 \mathrm{lymph}$ nodes are examined. ${ }^{13,14}$ In contrast, guidelines for managing lymph nodes in patients with esophageal cancer are lacking. We speculate that the differences in the total number of lymph nodes identified is likely a function of the difference in staging systems in which pathologists are encouraged to evaluate 15 nodes for gastric cancers (and no such criteria exist for esophageal carcinomas). In the gastric cancer staging system up to 6 positive nodes is still considered N1 disease. In the esophageal staging system this is not the case. In the esophagus node number and location have the potential for rapid spread because of a rich lymphatic network and lack of serosa. Another factor that might affect the resection rate as well is that in patients with gastric cancer, a clinically positive perigastric lymph node would not preclude primary surgical resection. However, a similar patient with a periesophageal node clinically positive at the distal esophagus would be in a higher stage and currently treated differently.

\section{Limitations}

Our study has several limitations, some of which are inherent limitations of the SEER database. The SEER database does not collect data on a number of important prognostic variables, including comorbidities, hospital volume, and use of chemotherapy. ${ }^{20-22}$ Therefore we could not adjust for these variables in our survival analysis. It is possible that tumor location might have been misclassified in patients who did not undergo esophagectomy or gastrectomy because the SEER database does not mandate endoscopic validation. We used the AJCC staging systems in our multivariate survival analysis. However, DE and GC adenocarcinomas have different AJCC staging systems, which could confound our results. ${ }^{2}$ When we used the SEER historic staging system, our results were unchanged, indicating that the differences in AJCC staging were not a significant source of confounding.

\section{CONCLUSIONS}

Through a large, population-based analysis of the SEER database, we found that $\mathrm{DE}$ and $\mathrm{GC}$ adenocarcinomas have similar overall and cancer-specific patient survival rates. This argues that adenocarcinomas of the GEJ are not distinct entities delineated by anatomic boundaries. We recommend that the same surgical oncology principles (adequate staging, en bloc resection with appropriate margins, and an adequate lymphadenopathy) should be applied to the treatment of tumors of both locations.

We thank Mary Knatterud, $\mathrm{PhD}$, for her editorial assistance with this manuscript.

\section{References}

1. Siewert JR, Stein HJ. Classification of adenocarcinoma of the oesophagogastric junction. Br J Surg. 1998;85:1457-9.

2. Greene FL. AJCC cancer staging manual. 6th ed. New York: Springer-Verlag; 2002.

3. Surveillance, Epidemiology, and End Results (SEER) Program. Limited-use data (1973-2005), National Cancer Institute, DCCPS, Surveillance Research Program, Cancer Statistics Branch, released April 2006, based on the November 2005 submission. Available at: www.seer.cancer.gov. Accessed April 2008.

4. Fritz A, Percy C, Jack A, Shanmugaratnam K, Sobin L, Parkin DM, et al. International classification of diseases for oncology. 3rd. ed. Geneva: World Health Organization; 2000.

5. Ellis FH Jr, Heatley GJ, Krasna MJ, Williamson WA, Balogh K. Esophagogastrectomy for carcinoma of the esophagus and cardia: a comparison of findings and results after standard resection in three consecutive eight-year intervals with improved staging criteria. J Thorac Cardiovasc Surg. 1997;113:836-48.

6. Graham AJ, Finley RJ, Clifton JC, Evans KG, Fradet G. Surgical management of adenocarcinoma of the cardia. Am J Surg. 1998;175:418-21.

7. Hagen JA, DeMeester SR, Peters JH, Chandrasoma P, DeMeester TR. Curative resection for esophageal adenocarcinoma: analysis of 100 en bloc esophagectomies. Ann Surg. 2001;234:520-31.

8. Mariette C, Castel B, Balon JM, Van Seuningen I, Triboulet JP. Extent of oesophageal resection for adenocarcinoma of the oesophagogastric junction. Eur $J$ Surg Oncol. 2003;29:588-93.

9. Rudiger Siewert J, Feith M, Werner M, Stein HJ. Adenocarcinoma of the esophagogastric junction: results of surgical therapy based on anatomical/topographic classification in 1,002 consecutive patients. Ann Surg. 2000;232: 353-61.

10. Barbour AP, Rizk NP, Gonen M, Tang L, Bains MS, Rusch VW, et al. Adenocarcinoma of the gastroesophageal junction: influence of esophageal resection margin and operative approach on outcome. Ann Surg. 2007;246:1-8.

11. Ito H, Clancy TE, Osteen RT, Swanson RS, Bueno R, Sugarbaker DJ, et al. Adenocarcinoma of the gastric cardia: what is the optimal surgical approach? J Am Coll Surg. 2004; 199:880-6.

12. Law S, Arcilla C, Chu KM, Wong J. The significance of histologically infiltrated resection margin after esophagectomy for esophageal cancer. Am J Surg. 1998; 176:286-90.

13. Cuschieri A, Weeden S, Fielding J, Bancewicz J, Craven J, Joypaul V, et al. Patient survival after D1 and D2 resections for gastric cancer: long-term results of the MRC randomized surgical trial. Surgical Co-operative Group. Br J Cancer. 1999; 79:1522-30.

14. Hartgrink HH, van de Velde CJ, Putter H, Bonenkamp JJ, Klein Kranenbarg E, Songun I, et al. Extended lymph node dissection for gastric cancer: who may benefit? Final results of the randomized Dutch gastric cancer group trial. J Clin Oncol. 2004;22:2069-77.

15. Nakamura K, Ueyama T, Yao T, Xuan ZX, Ambe K, Adachi Y, et al. Pathology and prognosis of gastric carcinoma. Findings in 10,000 patients who underwent primary gastrectomy. Cancer. 1992;70:1030-7.

16. Sano T, Sasako M, Yamamoto S, Nashimoto A, Kurita A, Hiratsuka M, et al Gastric cancer surgery: morbidity and mortality results from a prospective randomized controlled trial comparing D2 and extended para-aortic lymphadenectomy_Japan Clinical Oncology Group study 9501. J Clin Oncol. 2004; 22:2767-73 
17. Hulscher JB, van Sandick JW, de Boer AG, Wijnhoven BP, Tijssen JG, Fockens $\mathrm{P}$, et al. Extended transthoracic resection compared with limited transhiatal resection for adenocarcinoma of the esophagus. N Engl J Med. 2002;347: 1662-9.

18. Altorki N, Kent M, Ferrara C, Port J. Three-field lymph node dissection for squamous cell and adenocarcinoma of the esophagus. Ann Surg. 2002;236: 177-83.

19. Lerut T, Nafteux P, Moons J, Coosemans W, Decker G, De Leyn P, et al. Threefield lymphadenectomy for carcinoma of the esophagus and gastroesophageal junction in $174 \mathrm{R} 0$ resections: impact on staging, disease-free survival, and outcome: a plea for adaptation of TNM classification in upper-half esophageal carcinoma. Ann Surg. 2004;240:962-74.
20. Macdonald JS, Smalley SR, Benedetti J, Hundahl SA, Estes NC, Stemmermann GN, et al. Chemoradiotherapy after surgery compared with surgery alone for adenocarcinoma of the stomach or gastroesophageal junction. N Engl J Med. 2001;345:725-30.

21. Graham AJ, Shrive FM, Ghali WA, Manns BJ, Grondin SC, Finley RJ, et al. Defining the optimal treatment of locally advanced esophageal cancer: a systematic review and decision analysis. Ann Thorac Surg. 2007;83:1257-64.

22. Cunningham D, Allum WH, Stenning SP, Thompson JN, Van de Velde CJ, Nicolson $\mathrm{M}$, et al. Perioperative chemotherapy versus surgery alone for resectable gastroesophageal cancer. N Engl J Med. 2006;355:11-20.

23. Wijnhoven BP, Siersema PD, Hop WC, van Dekken H, Tilanus HW. Adenocarcinomas of the distal oesophagus and gastric cardia are one clinical entity. Rotterdam Oesophageal Tumour Study Group. Br J Surg. 1999;86:529-35. 